\title{
Short Communication: The Nature of Heptadecenoic Acid in Ruminant Fats
}

\author{
S. P. Alves, C. Marcelino, P. V. Portugal, and R. J. B. Bessa ${ }^{1}$ \\ Estação Zootécnica Nacional, Instituto Nacional de Investigação Agrária e das Pescas, \\ 2005-048 Vale de Santarém, Portugal
}

\begin{abstract}
Heptadecenoic acid (17:1) is a minor constituent of ruminant fats and its isomeric definition remains undefined in most reports on ruminant milk and intramuscular fat. Samples of milk and intramuscular fat of bovine, ovine, and caprine origin were analyzed by gas chromatography (GC) using 3 capillary columns with and without addition of 17:1 cis-10. Additionally, cis isomers of ovine milk fat samples were isolated as methyl esters by preparative thin-layer chromatography and analyzed by GC. The structural analysis of $17: 1$ present in samples was achieved by chemical ionization tandem mass spectrometry techniques. The isomer $17: 1 \mathrm{cis}-9$ is the overwhelming heptadecenoic isomer in ruminant milk and intramuscular fat; $17: 1$ cis-10 is virtually absent. Moreover, current GC methods were able to resolve cis-9 from cis-10 and cis-8 isomers, so reports on $17: 1$ contents in ruminant fat should define its isomeric composition.
\end{abstract}

Key words: gas chromatography-tandem mass spectrometry, heptadecenoic acid, milk fat, muscle

Heptadecenoic acid (17:1) has long been recognized as minor constituent of ruminant fats (Shorland and Jessop, 1955). Recently it was proposed, along with other odd-chain fatty acids, as a potential marker of microbial biomass (Vlaeminck et al., 2005). The oddchain fatty acids are assumed to be mainly of rumen microbial origin and, after intestinal absorption, they are deposited in tissues or exported to milk fat. However, the origin of 17:1 is not clear. Recently Fievez et al. (2003) suggested that it could be an endogenous product of $\Delta^{9}$-desaturation of heptadecanoic acid (17:0). This would imply that the main 17:1 isomer in ruminant fats is $17: 1 \mathrm{cis}-9$. However, in spite of the earliest reports indicating that $17: 1 \mathrm{cis}-9$ is the main isomer in ruminant fat (Hansen et al., 1960; Hay and Morrison, $1970,1973)$, most of the recent reports are ambiguous.

Received July 1, 2005.

Accepted August 30, 2005

${ }^{1}$ Corresponding author: rjbbessa@mail.telepac.pt
In fact, most reports either do not present $17: 1$ or leave it undefined, whereas others call it 17:1 cis-10 (Franklin et al., 1999; Marks et al., 2004; Loor et al., 2005). The fact that the methyl ester standard available from commercial chemical companies is the cis-10 isomer, which probably coelutes with cis-9 isomer in some gas chromatography (GC) systems certainly contributes to the ambiguity. Our objective was to clarify which 17:1 isomers are predominant in ruminant fats through GC chemical ionization-tandem mass spectrometry techniques and to determine if common GC conditions can resolve $17: 1$ isomers.

Samples tested were chosen from several experimental sets analyzed for fatty acid composition in our laboratory, and included milk fat from bovine, ovine, and caprine, and intramuscular fat of lambs, kids, and beef. Lipid extraction in samples was conducted according to Folch et al. (1957) and methyl esters were prepared using a base-catalyzed transesterification procedure described by Christie (1993). The cis isomers of ovine milk fat were separated by preparative TLC on plates impregnated with $20 \% \mathrm{AgNO}_{3}$ and were located by spraying with $2^{\prime}, 7^{\prime}$-dichlorofluorescein solution in isopropanol. Samples were also spiked with 17:1 cis-10 standard obtained from Sigma Chemical Co. (St. Louis, MO). Fatty acid methyl esters were resolved in 3 GC systems: 1) Varian Saturn 2000 (Varian Inc., Walnut Creek, CA) equipped with ion-trap mass detector and a BPX-70 (SGE Chromatography Supplies, Austin, TX) capillary column $(60 \mathrm{~m}, 0.25 \mathrm{~mm}$ i.d., $0.25-\mu \mathrm{m}$ film thickness); 2) Agilent HP6890 (Agilent Tech. Inc., Palo Alto, CA) equipped with a flame-ionization detector and a CP-Sil 88 (Chrompack CP 7489, Varian Inc.) capillary column (100 m, $0.25 \mathrm{~mm}$ i.d., 0.20- $\mu \mathrm{m}$ film thickness); and 3) Varian 3800 GC equipped with a flame-ionization detector and an OmegaWax 250 (Supelco, Bellefont, CA) capillary column $(30 \mathrm{~m}, 0.25 \mathrm{~mm}$ i.d., $0.25-\mu \mathrm{m}$ film thickness). Helium was the carrier gas in all systems.

Structural analysis of 17:1 methyl ester isomers was conducted in the chemical ionization-tandem mass spectrometry mode of the Varian Saturn 2000 system. Ion-trap parameters used in all analyses presented included: trap temperature, $170^{\circ} \mathrm{C}$; manifold temperature, $80^{\circ} \mathrm{C}$; transfer line temperature, $200^{\circ} \mathrm{C}$; and axial 

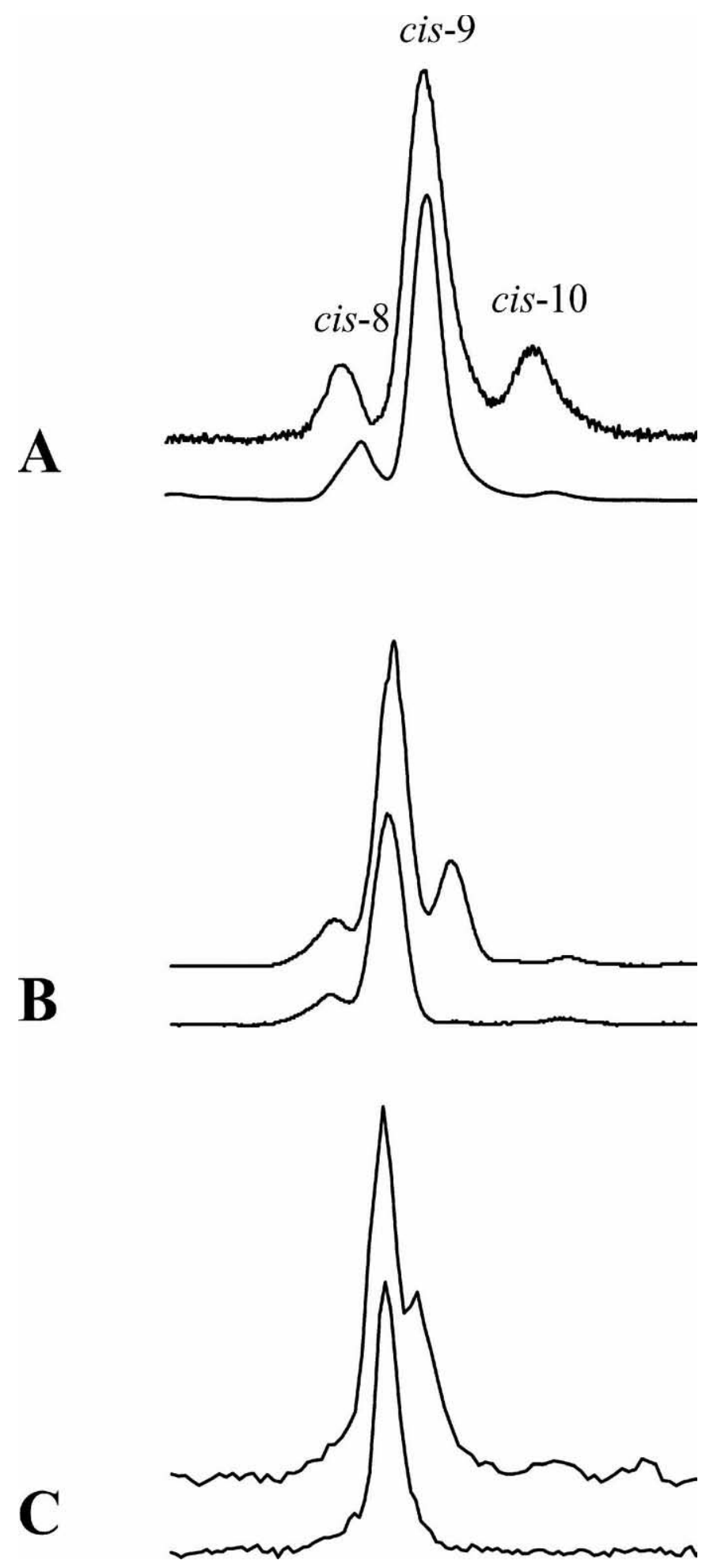

Figure 1. Partial chromatogram of the 17:1 region of the cis fraction of ovine milk fat sample analyzed using 3 different columns: 100-m CP-Sil 88 (A), 30-m OmegaWax (B), and 60-m BPX-70 (C). The lower curve in each panel represents the sample, and the upper curve represents the sample spiked with 17:1 cis-10 standard.

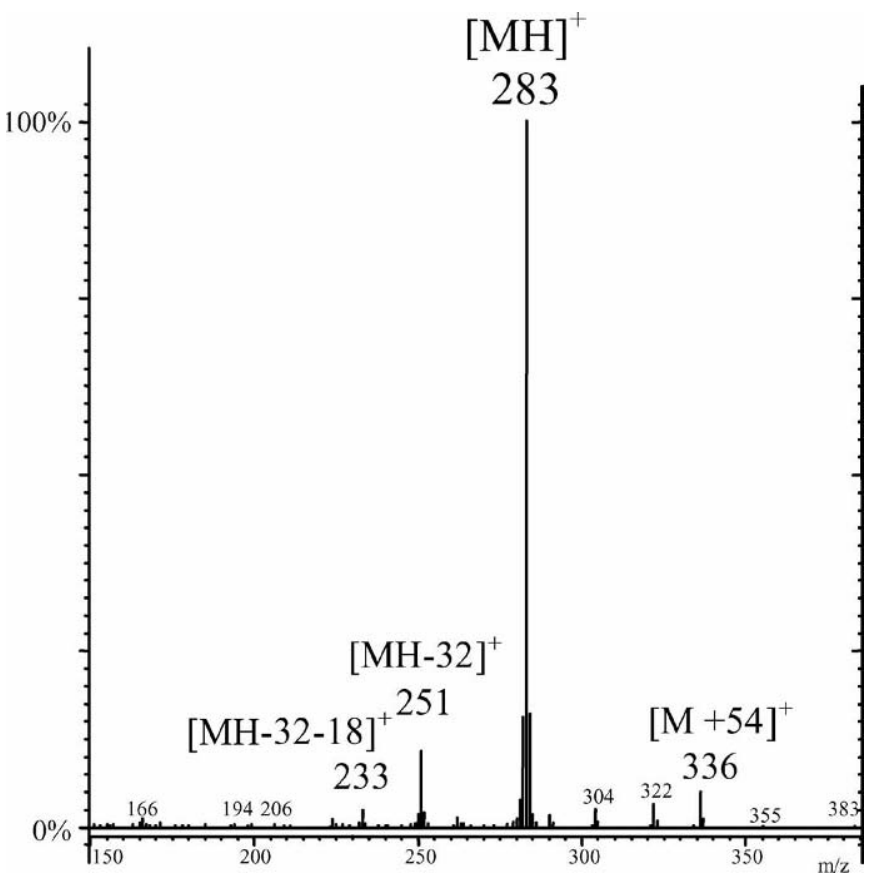

Figure 2. Acetonitrile chemical ionization-mass spectrum of 17:1 cis-9 methyl ester of ovine milk fat sample, showing the ions [MH$32-18]^{+},[\mathrm{MH}-32]^{+}, \mathrm{MH}^{+}$, and $[\mathrm{M}+54]^{+}$.

modulation amplitude, $3.8 \mathrm{~V}$. Acetonitrile was used as chemical ionization $(\mathbf{C I})$ reagent gas with the following CI parameters: CI storage level, $19 \mathrm{~m} / \mathrm{z}$; ejection amplitude, $15 \mathrm{~m} / \mathrm{z}$; maximum ionization time, 2,000 $\mu$ sec; maximum reaction time, $40 \mathrm{~ms}$; prescan ionization time, $200 \mu \mathrm{sec}$; and target total ion current, 5,000 counts. Additional tandem mass spectrometry parameters were as follows: emission current, $40 \mu \mathrm{A}$; scan time, $0.34 \mathrm{~s}$; mass isolation window, $3 \mathrm{~m} / \mathrm{z}$; and excitation storage level, $85 \mathrm{~m} / \mathrm{z}$. The resonant excitation amplitudes used to collisionally dissociate the $(\mathrm{M}+54)^{+}$ions varied from 1.60 to $2.0 \mathrm{~V}$.

Samples of ovine, bovine, and caprine origin were resolved in the $3 \mathrm{GC}$ systems with and without addition of 17:1 cis-10 methyl ester standard (Figure 1). The presence of cis-10 isomer was not detected in all samples studied. All samples spiked with 17:1 cis-10 showed a well-defined peak (presumably 17:1 cis-9) and occasionally other minor peaks (presumably 17:1 cis-8) preceding the 17:1 cis-10 peak. Thin-layer chromatography isolation of the cis fraction of ovine milk fat samples allowed the evidence of the $c i s-8$ isomer peak. Precht and Molkentin (2000), using a 100-m CP-Sil 88 column, reported good resolution between cis-8 and cis-9 17:1 isomers in human milk fat. Hay and Morrison (1970) reported that cis-8 was the second major 17:1 isomer in cow milk fat, comprising $20.1 \%$ of total heptadecenoates. We found in the cis fraction of ovine milk that 


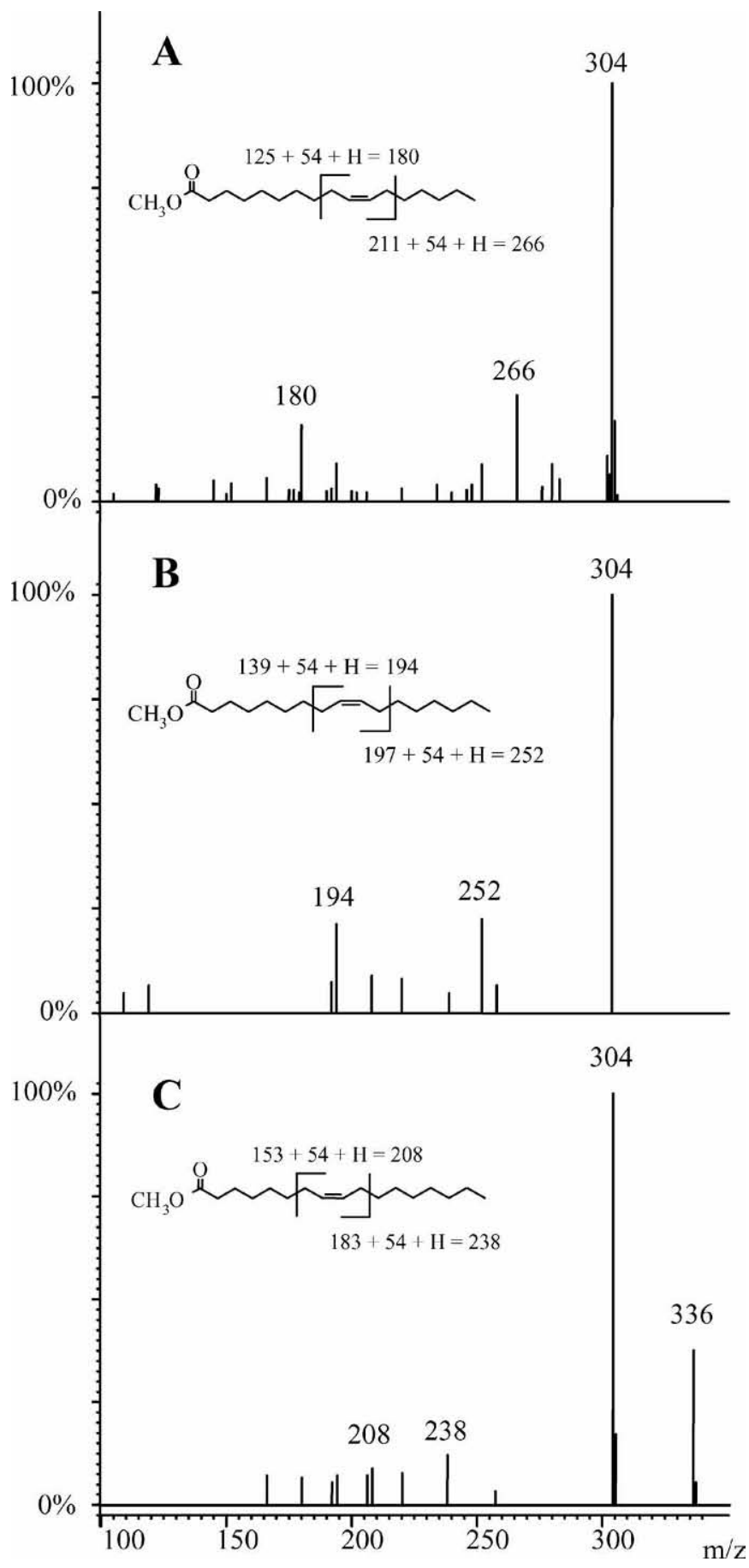

Figure 3. Acetonitrile chemical ionization-tandem mass spectra for 17:1 cis-10 methyl ester standard (A) and for 17:1 cis-9 (B) and 17:1 cis-8 (C) methyl esters from ovine milk fat sample. The base peak corresponds to a loss of methanol from the parent ion, and is identified by its strong intensity at $\mathrm{m} / \mathrm{z} 304\left([\mathrm{M}+54-32]^{+}\right)$.

the $c i s-8$ isomer peak area was about $15 \%$ of the cis-9 area. As shown in Figure 1, the 100-m CP-Sil 88 and the 30-m OmegaWax columns unequivocally resolved cis-10 and cis-9 isomers as well as a minor amount of cis8. The chromatographic resolution was less complete when the 60-m BPX-70 column was used.

The identification of the double bond position in monoenoic fatty acids isomers was determined from CI mass spectra using acetonitrile as CI reagent gas (Pelt and Brenna, 1999; Michaud et al., 2002). Under CI conditions, acetonitrile self-reacts in an ion-molecule reaction to produce a reagent ion of $\mathrm{m} / \mathrm{z} 54\left(\mathrm{H}_{2} \mathrm{C}={ }^{+} \mathrm{N}=\mathrm{C}=\right.$ $\mathrm{CH}_{2}$ ), which reacts selectively with the analyte double bond to yield an $[\mathrm{M}+54]^{+}$molecular species (Figure 2). Collision dissociation of the $[\mathrm{M}+54]^{+}$ion by CI-tandem mass spectrometry yields 2 diagnostic fragments (Figure 3) allowing unambiguous localization of the double bond. Figure 3 presents CI-tandem mass spectrometry spectra of standard 17:1 cis-10 (panel A), 17:1 cis-9 (panel B) and cis-8 (panel C) of ovine milk fat samples. The diagnostic ions for the cis-9 isomer appear at $\mathrm{m} / \mathrm{z}$ 252 and 194, respectively, and analogous ions for the cis-10 standard isomer occur at $\mathrm{m} / \mathrm{z} 266$ and 180, respectively. The resolution of cis-8 isomer was not perfect with the 60-m BPX 70 column (Figure 1), but it was possible to identify the expected diagnostic ions $(\mathrm{m} / \mathrm{z}$ 238 and 208).

In all samples of ovine, bovine, and caprine origin, the CI-tandem mass spectrometry studies indicated that the main $17: 1$ peak was $17: 1$ cis-9. We concluded that $17: 1 \mathrm{cis}-9$ is the overwhelming heptadecenoic isomer in ruminant milk and intramuscular fat, and that $17: 1$ cis-10 is virtually absent. Moreover, current GC methods were able to resolve cis-9 from cis-10 and cis8 isomers, so published reports on 17:1 contents in ruminant fat should define its isomeric composition.

\section{ACKNOWLEDGMENT}

Financial support by project AGRO/2003/512 is acknowledged.

\section{REFERENCES}

Christie, W. W. 1993. Preparation of ester derivatives of fatty acids for chromatographic analysis. Pages 69-111 in Advances in lipid methodology-2. W. W. Christie, ed. Oily Press, Dundee, UK.

Fievez, V., B. Vlaeminck, M. S. Dhanoa, and R. J. Dewhurst. 2003. Use of principal component analysis to investigate the origin of heptadecenoic and conjugated linoleic acids in milk. J. Dairy Sci. 86:4047-4053.

Folch, J., M. Lees, and G. H. S. Stanley. 1957. Simple method for the isolation and purification of total lipids from animal tissues. J. Biol. Chem. 226:497-509.

Franklin, S. T., K. R. Martin, R. J. Baer, D. J. Schingoethe, and A. R. Hippen. 1999. Dietary marine algae (Schizochytrium sp.) increases concentrations of conjugated linoleic, docosahexaenoic and transvaccenic acids in milk of dairy cows. J. Nutr. 129:2048-2054.

Hansen, R. P., F. B. Shorland, and M. H. Cooley. 1960. Isolation of cisdelta-9 heptadecenoic acid from butterfat. Biochem. J. 77:64-66. 
Hay, J. D., and W. R. Morrison. 1970. Isomeric monoenoic fatty acids in bovine milk fat. Biochim. Biophys. Acta 202:237-243.

Hay, J. D., and W. R. Morrison. 1973. Positional isomers of cis and trans monoenoic acids from ox (steer) perinephric fat. Lipids 8:94-95.

Loor, J. J., A. Ferlay, A. Ollier, M. Doreau, and Y. Chilliard. 2005. Relationship among trans and conjugated fatty acids and bovine milk fat yield due to dietary concentrate and linseed oil. J. Dairy Sci. 88:726-740.

Marks, D. J., M. L. Nelson, J. R. Busboom, J. D. Cronrath, and L. Falen. 2004. Effects of supplemental fats on growth performance and quality of beef from steers fed barley-potato product finishing diets. II. Fatty acid composition of muscle and subcutaneous fat. J. Anim. Sci. 82:3611-3616.

Michaud, A. L., G.-Y. Diau, R. Abril, and J. T. Brenna. 2002. Double bond localization in minor homoallylic fatty acid methyl esters using acetonitrile chemical ionization tandem mass spectrometry. Anal. Biochem. 307:348-360.

Pelt, C. K. V., and J. T. Brenna. 1999. Acetonitrile chemical ionization tandem mass spectrometry to locate double bonds in polyunsaturated fatty acids methyl esters. Anal. Chem. 71:1981-1989.

Precht, D., and J. Molkentin. 2000. Identification and quantification of cis/trans C16:1 and C17:1 fatty acid positional isomers in German human milk lipids by thin-layer chromatography and gas chromatography/mass spectrometry. Eur. J. Lipid Sci. Technol. 102:102-113.

Shorland, F. B., and A. S. Jessop. 1955. Isolation of $\Delta-9$ heptadecenoic acid from lamb caul fat. Nature 176:737.

Vlaeminck, B., C. Dufour, A. M. Van Vuuren, A. R. J. Cabrita, R. J. Dewhurst, D. Demeyer, and V. Fievez. 2005. Use of odd and branched-chain fatty acids in rumen contents and milk as a potential microbial marker. J. Dairy Sci. 88:1031-1042. 